\title{
Cebado profiláctico de catéteres permanentes: ¿causa de obstrucción?
}

Mª Ángeles López López - Neus Franch Cuiraneta - Ma Antonia Bauzá Capellá - Ma José Alcantud García

Hospital Universitario "Son Dureta". Palma de Mallorca

\section{Sra Directora:}

En la actualidad, en las unidades de Diálisis, nos encontramos con un gran número de pacientes portadores de catéteres permanentes, con el consecuente aumento en el riesgo de infección, lo que nos ha llevado a tener más inquietud para realizar estudios para prevenir dichas infecciones.

En la unidad de Diálisis del Hospital Son Dureta de Palma de Mallorca, la forma de sellado de los catéteres permanentes hasta diciembre de 2004, se realizaba con un lavado por arrastre con suero fisiológico en cada luz y, posteriormente, cebado con heparina sódica al $5 \%$, pero a partir de enero de 2005 esto cambió, introduciéndose una nueva forma de sellado de los catéteres en la que añadíamos antibioterapia profiláctica.

Esto ha supuesto un aumento en el número de coagulación de los catéteres, lo que ha dado lugar a un aumento considerable en el número de catéteres malfuncionantes que se tenían que repermeabilizar utilizando urokinasa. A consecuencia de la implantación de este nuevo método de sellado de los catéteres, decidimos realizar el presente estudio, para lo que utilizamos la hoja de registro de Enfermería de Hemodiálisis, con el objetivo de

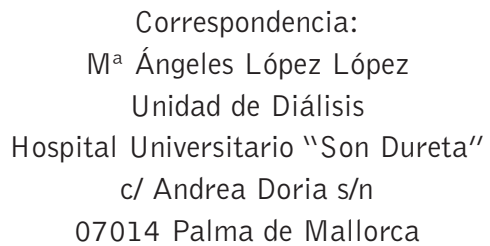

comparar el consumo de urokinasa dependiendo del método empleado para el sellado de los catéteres tunelizados, ya sea solamente con heparina o bien con heparina + antibiótico.

Para esto se ha realizado a los pacientes de la unidad de crónicos que portaban un catéter tunelizado un estudio retrospectivo transversal desde enero de 2004 hasta diciembre de 2005 comparando las dos formas de sellado de los catéteres:

- Año 2004: Heparina sódica al 5\% 10.000 UI, que equivalen a $2 \mathrm{ml}$ por luz.

- Año 2005: Heparina sódica al 5\% 7.500 UI que equivalen a $1,5 \mathrm{ml}+$ gentamicina $2 \mathrm{mg}$, que equivalen a $0,5 \mathrm{ml}$ haciendo un total de $2 \mathrm{ml}$ por luz.

\section{Resultados}

En el año 2004 fueron 162 pacientes, de los cuales 80 eran hombres y 82 mujeres con un total de 2.085 sesiones de hemodiálisis al año mientras que en el año 2005 fueron 225 pacientes, de los cuales 87 eran hombres y 139 mujeres con un total de 2.904 sesiones de hemodiálisis al año.

La tabla 1 nos muestra el número de pacientes dializados, el total de hemodiálisis así como el total de unidades de urokinasa utilizadas por paciente/año, tanto del año 2004 como del 2005 y como se observa, hay un aumento considerable de unidades de urokinasa utilizadas por paciente y año durante el 2005. 


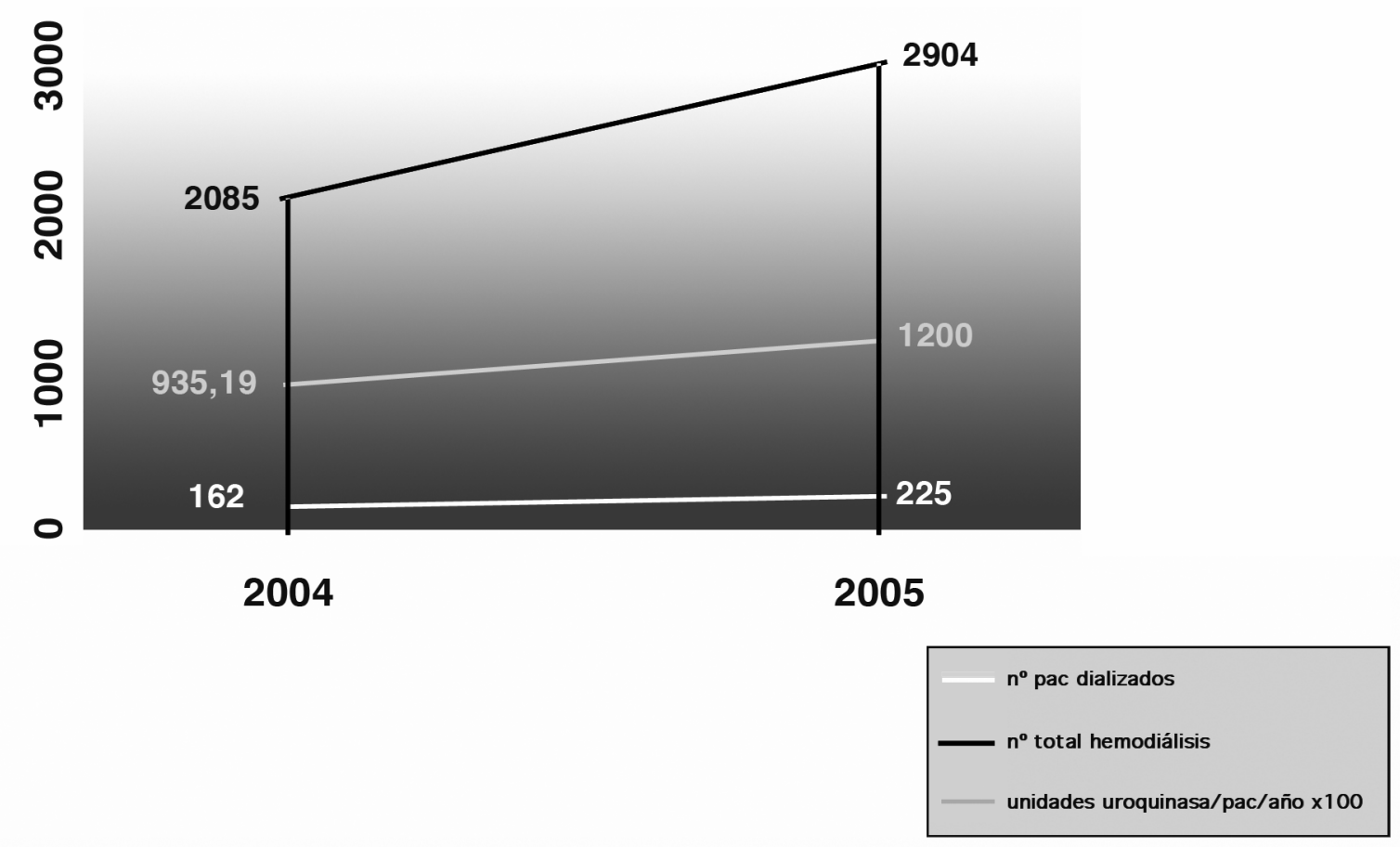

Tabla 1. Pacientes dializados, número total de hemodiálisis practicadas y unidades de urokinasa utilizadas por paciente y año en 2004 y 2005

Podemos pues observar que hay un claro incremento en la utilización de urokinasa cuando el catéter es sellado con heparina + antibiótico, lo que implica un aumento del coste económico y unos posibles efectos secundarios propios de la urokinasa como es la descoagulación. Por tanto, una mejor solución podría ser utilizar urokinasa en vez de heparina sódica para el sellado de los catéteres, aunque se debería estudiar cual es la cantidad mínima necesaria para evitar la coagulación del catéter, teniendo en cuenta el coste y la potencia anticoagulante de la urokinasa.

En nuestros resultados no se aprecia una disminución en el número de infecciones, pero para ratificar este dato se debería ampliar el estudio con otras variables que no hemos tenido en cuenta.

\section{Bibliografía}

1. Martín A, Bartolomé MC, Tamerón A. Urokinasa aplicada de forma precoz, "clave" para la desobstrucción de catéteres permanentes. Rev Soc Esp Enferm Nefrol. 2005; 8(2):98-102.

2. Rodríguez Hernández JA, Gutierrez Julián JM. Guía de acceso vascular en Hemodiálisis. SEN. 2004. 